\title{
GEOTECHNICAL CHARACTERISTICS OF EFFLUENT CONTAMINATED COHESIVE SOILS
}

\author{
Muhammad Imran KHAN ${ }^{\mathrm{a}, \mathrm{b}}$, Muhammad IRFAN ${ }^{\mathrm{a}}$, Mubashir AZIZc ${ }^{\mathrm{c}}$, Ammad Hassan KHAN ${ }^{\mathrm{d}}$ \\ ${ }^{a}$ Department of Civil Engineering, University of Engineering and Technology, Lahore, Pakistan \\ ${ }^{b}$ Department of Civil Engineering and Applied Mechanics, McGill University, Montreal, Canada \\ ${ }^{c}$ Department of Civil Engineering, Al Imam Mohammad Ibn Saud Islamic University, Riyadh, Saudi Arabia \\ ${ }^{d}$ Department of Transportation Engineering and Planning, \\ University of Engineering and Technology, Lahore, Pakistan
}

Submitted 23 Dec. 2015; accepted 04 Jul. 2016

\begin{abstract}
In developing countries like Pakistan, raw industrial effluents are usually disposed-off directly into open lands or in water bodies resulting in soil contamination. Leachate formation due to rainfalls in openly dumped solid waste also adds to soil contamination. In this study, engineering behavior of soils contaminated by two industrial effluents, one from paper industry (acidic) and another from textile industry (basic), has been investigated. Laboratory testing revealed significant effects of effluent contamination on engineering behavior of tested soils. Liquid limit, plasticity index, optimum moisture content and compression index of tested soils were found to increase with effluent contaminant, indicating a deterioration in the engineering behavior of soils. Whereas maximum dry density, undrained shear strength and coefficient of consolidation of the contaminated soils showed a decreasing trend. The dilapidation in engineering characteristics of soils due to the addition of industrial effluents could pose serious threats to existing and future foundations in terms of loss of bearing capacity and increase in settlement.
\end{abstract}

Keywords: soil contamination, industrial waste, engineering behavior, effluent waste, leachate.

\section{Introduction}

Industries play a vital role in the development of any country. However, the industrial waste, if released to the environment untreated, may result in several environmental and health hazards. In developed countries, reinforcement of environmental laws and ample resources ensure proper treatment of industrial waste before releasing it to the environment. However, the industrial effluents are often discharged untreated which contaminate water channels and ultimately the soil through seepage.

Industrial sector of Pakistan contributes about $24 \%$ of GDP and a huge volume of effluent waste is being generated from various industries. This contaminated effluent waste may carry poisonous or harmful substances like chromium, sulfides, free chlorine, lead, chromium etc. (Bond et al. 1973). Although environmental regulations, outlining the necessary treatment for industrial effluents exist in the country, yet their implementation in true sense remains distant from reality. Unfortunately, most of the waste from industries is discharged to the local environment untreated. Besides their effects on the quality of drinking water, which always remains the prime concern, effluents also affect the engineering properties of surrounding soils through seepage. Previous work (Adebisi, Fayemiwo 2010; Gratchev, Towhata 2009; Jia et al. 2011; Khamehchiyan et al. 2007; Naeini, Jahanfar 2011; Nazir 2011; Olgun, Yildız 2010; Patel 2011; Reddy et al. 2011; Sunil et al. 2006, 2009) has shown that the index and engineering properties of contaminated soils tend to alter due to chemical reactions between the soil minerals and the contaminant. Soil contamination may also be detrimental to foundation material (Sunil et al. 2006, 2009). Rapid urbanization in various metropolitans of Pakistan is forcing the developers to construct at places which have been used as dumping sites of such industrial effluents. Special considerations, with reference to the modifications in engineering behavior of such soils, are required to be taken into account for design and construction of foundations on such soils. 
The main objective of this study is therefore to explore the effects of industrial effluents on the geotechnical properties of local cohesive soils. Considering the widespread paper and textile industry in Pakistan, effluents from these industries are employed in this study. Contaminated soil specimens were prepared by adding various proportions of industrial effluents in the virgin soil samples and their effects on various engineering properties of contaminated soils are investigated.

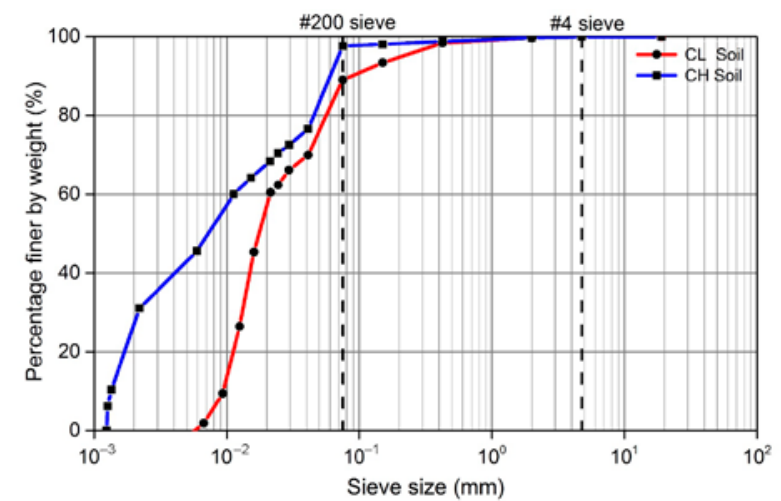

Fig. 1. Grain size distribution of D.G Khan (CL) and Nandipur $(\mathrm{CH})$ soil samples

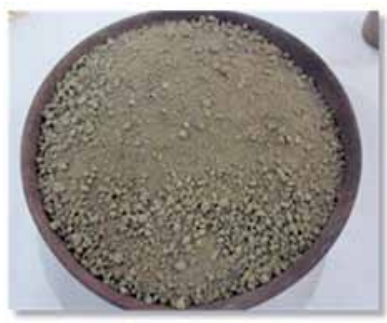

(a)

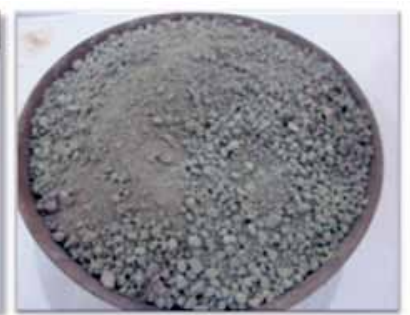

(b)
Fig. 2. Photographs (a) Soil sample from D.G. Khan (CL), (b) Soil sample from Nandipur $(\mathrm{CH})$

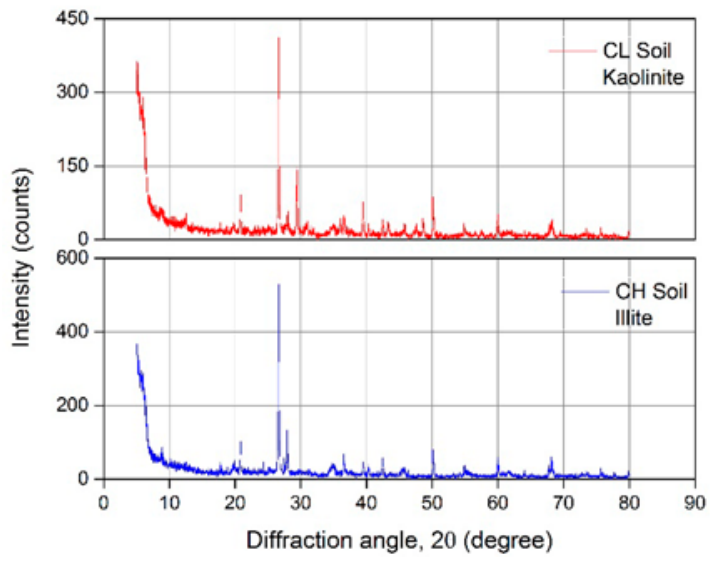

Fig. 3. X-ray diffraction analysis of soil samples

\section{Materials}

\subsection{Soil samples}

Soil samples were collected from D.G. Khan and Nandipur (Pakistan). Grain size distribution of both soils are shown in Figure 1 and were classified as CL / A-6(10) and CH / A-7-6 (20) as per USCS / AASHTO soil classification systems, respectively. Actual photographs of both soil samples are shown in Figure 2. Soil samples were collected from test pits at $0.6 \mathrm{~m}$ depth. The samples were not collected from natural ground surface in order to avoid the presence of any organic matter in the form of roots, vegetation, leaves etc. X-ray diffraction (XRD) analysis of soil samples (Fig. 3) revealed the presence of kaolinite in CL soil and illite in $\mathrm{CH}$ soil as dominant mineral. Physical and Chemical Properties of soil samples are summarized in Table 1.

Table 1. Physical and chemical properties of the soil samples tested as per respective ASTM standard

\begin{tabular}{|c|c|c|c|}
\hline Description & Units & $\begin{array}{l}\text { D.G. Khan } \\
\text { Soil }\end{array}$ & $\begin{array}{l}\text { Nandipur } \\
\text { Soil }\end{array}$ \\
\hline $\begin{array}{l}\text { Natural moisture content, } \\
\text { NMC }\end{array}$ & $\%$ & 6 & 10 \\
\hline Fine contents (Silt + Clay) & $\%$ & 89 & 98 \\
\hline Liquid limit, $w_{L}$ & $\%$ & 37 & 58 \\
\hline Plastic limit, $w_{P}$ & $\%$ & 21 & 27 \\
\hline Plasticity index, $I_{P}$ & $\%$ & 16 & 31 \\
\hline Specific gravity & - & 2.645 & 2.717 \\
\hline USCS soil classification & - & CL & $\mathrm{CH}$ \\
\hline AASHTO soil classification & - & A-6 (10) & A-7-6 (20) \\
\hline $\begin{array}{l}\text { Maximum dry unit weight, } \\
\gamma_{d \max }\end{array}$ & $\mathrm{kN} / \mathrm{m}^{3}$ & 18.41 & 17.18 \\
\hline $\begin{array}{l}\text { Optimum moisture } \\
\text { content, } O M C\end{array}$ & $\%$ & 12.82 & 17.13 \\
\hline $\mathrm{pH}$ value & - & 7.5 & 7 \\
\hline Electrical conductivity, $E C$ & $\begin{array}{c}\mu \\
\text { Simen }\end{array}$ & 849 & 228 \\
\hline Sulphate content, $\mathrm{SO}_{4}$ & $\%$ & 0.04 & 0.02 \\
\hline Chloride content, $\mathrm{Cl}$ & $\%$ & 0.123 & 0.015 \\
\hline Organic matter content & $\%$ & 0.140 & 0.135 \\
\hline Calcium content, $\mathrm{Ca}$ & $\%$ & 0.014 & 0.007 \\
\hline Magnesium content, $M g$ & $\%$ & 0.004 & 0.002 \\
\hline Total dissolved solids, TDS & $\%$ & 0.011 & 0.005 \\
\hline $\begin{array}{l}\text { XRD analysis (dominant } \\
\text { clay mineral) }\end{array}$ & - & Kaolinite & Illite \\
\hline
\end{tabular}

\subsection{Industrial effluents}

The main objective of this study was to investigate the effects of effluents from paper industry (Fig. 4 (a)) and textile industry (Fig. 4 (b)) on engineering properties of 


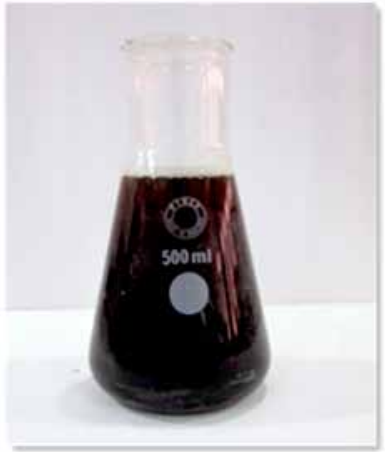

(a)

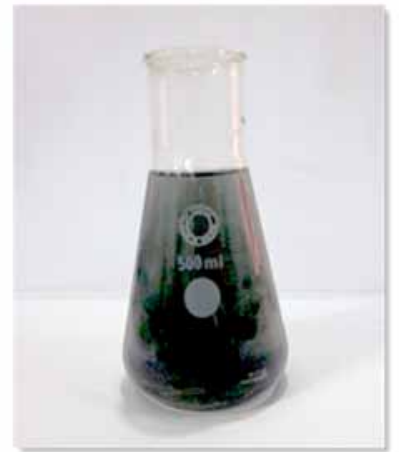

(b)
Fig. 4. (a) Effluent from paper industry (acidic in nature), (b) Effluent from textile industry (basic in nature)

cohesive soils. Effluents from paper industry are typically observed to be acidic (Kumar 2005), while the effluents from textile industry are commonly basic (Choudhury 2006). The representative industrial effluents were collected from Century Paper Mill, Lahore and Denim Textile, Lahore (Pakistan). The collected effluent samples were subjected to chemical examination, the summary of which as well as the respective national standards according to NEQS (2000) are presented in Table 2.

Table 2. Chemical properties of effluent samples

\begin{tabular}{|c|c|c|c|c|}
\hline Description & Units & $\begin{array}{c}\text { Textile } \\
\text { Industry } \\
\text { Effluent }\end{array}$ & $\begin{array}{c}\text { Paper } \\
\text { Industry } \\
\text { Effluent }\end{array}$ & $\begin{array}{l}\text { NEQS } \\
(2000)\end{array}$ \\
\hline $\begin{array}{l}\text { Calcium } \\
\text { content, } \mathrm{Ca}\end{array}$ & $\%$ & 0.002 & 0.012 & $-^{*}$ \\
\hline $\begin{array}{l}\text { Magnesium } \\
\text { content, Mg }\end{array}$ & $\%$ & 0.001 & 0.031 & $-^{*}$ \\
\hline $\begin{array}{l}\text { Chloride } \\
\text { content, } \mathrm{Cl}\end{array}$ & $\%$ & 0.098 & 0.125 & 0.10 \\
\hline $\begin{array}{l}\text { Sulphate } \\
\text { content, } \mathrm{SO}_{4}\end{array}$ & $\%$ & 0.012 & 0.016 & 0.10 \\
\hline $\mathrm{pH}$ & - & 11 & 3 & $6-9$ \\
\hline $\begin{array}{l}\text { Total dissolved } \\
\text { solids, TDS }\end{array}$ & $\%$ & 0.145 & 0.015 & 0.35 \\
\hline
\end{tabular}

Note: ${ }^{*}$ National guidelines do not exist.

\section{Experimental program}

A systematic procedure was established for the preparation of contaminated soil samples. Cohesive soil samples were first oven dried and pulverized. Industrial effluents were then mixed with soil samples in specified proportions of $0,5,10,15$ and $20 \%$ by dry weight of soil. The soil-effluent mixture was left for 48 hours to bring the moisture in equilibrium before laboratory testing. The contaminated soil samples were then air dried and sieved through $4.75 \mathrm{~mm}$ sieve. By adding different proportions of each effluent in each soil type, a total of 16 contaminated samples were prepared. A systematic nomenclature was adopted to represent the contaminated soil samples. The first two letters represent the soil type, either low plastic $(\mathrm{CL})$ or high plastic $(\mathrm{CH})$. Third letter represents the source of effluent (paper industry $(\mathrm{P})$ or textile industry (T)) and the digits at the end represent the percentage of effluent in each soil sample e.g. "CHP5" represents a high plastic clay sample with $5 \%$ contamination from paper industry. The contaminated soil samples plus the two original uncontaminated soils were then subjected to various tests in order to explore the effects of effluent contamination. Soil properties evaluated as part of this study included specific gravity, Atterberg limits, modified compaction, one-dimensional consolidation, unconfined compression, $\mathrm{pH}$ and electrical conductivity. All tests were performed according to the relevant ASTM standard.

\section{Results and discussions}

\subsection{Effect of contamination on Atterberg's limits and soil classification}

The addition of acidic (paper industry) and basic (textile industry) contaminants increased the plasticity of soil as shown in Figures 5 and 6. The liquid limit of CL soil increased by $13.5 \%$ and $10.8 \%$ with $20 \%$ acidic and basic contamination respectively. However, the corresponding increase in liquid limit of $\mathrm{CH}$ soil was not as pronounced and the increase in liquid limit was limited to $6.9 \%$ and $5.2 \%$ for acidic and basic contamination addition respectively.

Similarly, the plasticity index of both the soils showed an increasing trend with the addition of contaminants. The plasticity index of CL soil increased by $37.5 \%$ with the mixing of $20 \%$ acidic and basic contamination. However, the corresponding increase in plasticity index of $\mathrm{CH}$ soils was not as pronounced and the increase in plasticity index was limited to $22.6 \%$ and $19.4 \%$ for acidic and basic contaminants respectively.

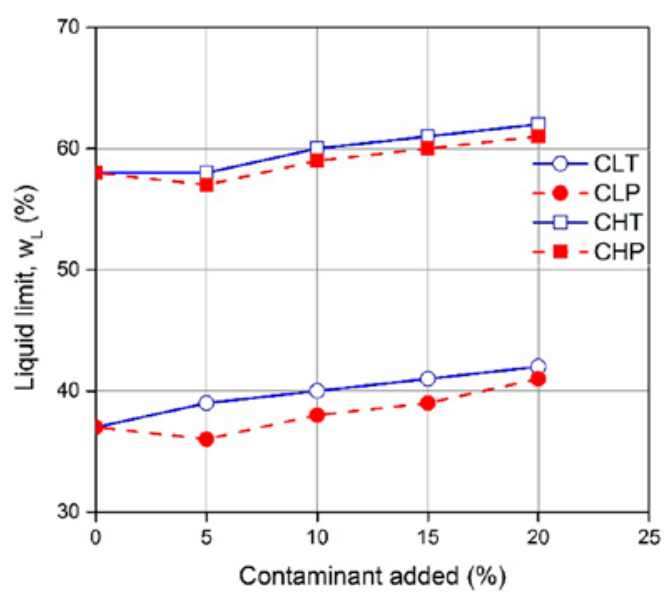

Fig. 5. Effect of contamination on liquid limit 
With effluent contamination, an increase in liquid limit is followed by a corresponding increase in plasticity index. Therefore, soil classification, as shown in Figure 7 does not change due to contamination.

The increase in Atterberg limits of soil is mainly because of the chemical action between soil particles and

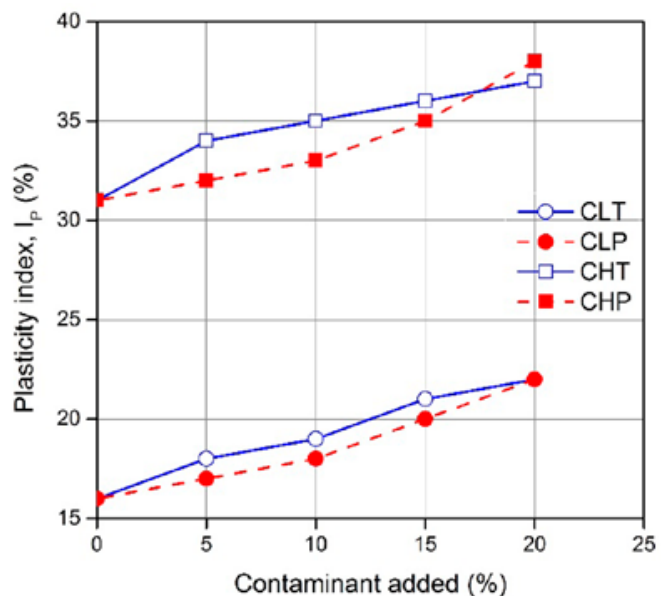

Fig. 6. Effect of contamination on plasticity index

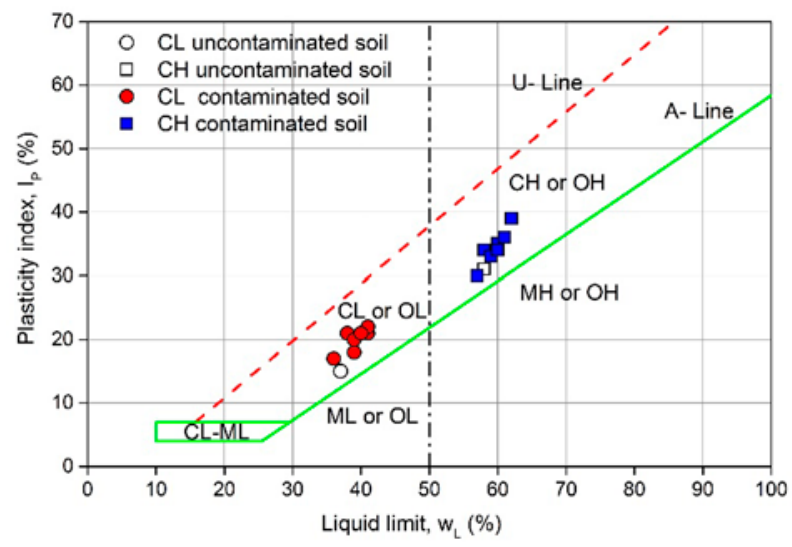

Fig. 7. Effect of contamination on soil classification

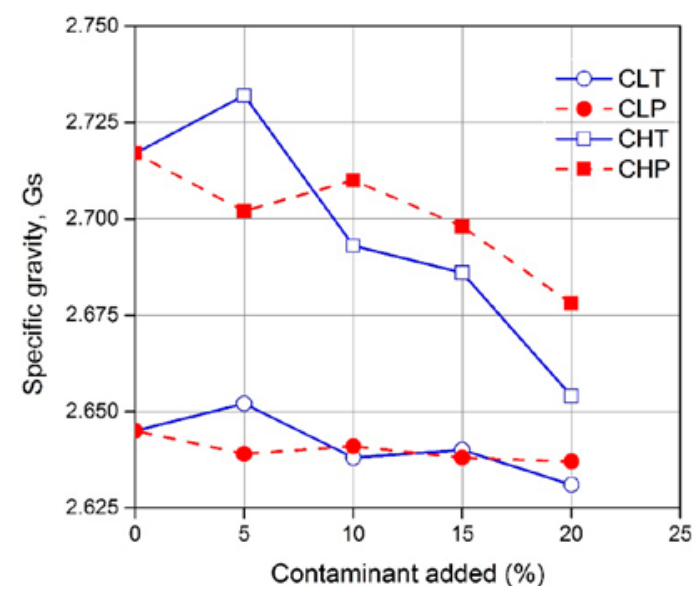

Fig. 8. Variation of specific gravity with concentration of contaminant effluent. The increase in liquid limit indicates an increase in consolidation potential of contaminated soils (Terzaghi, Peck 1948). High plasticity of contaminated soils also causes problems related to increased swell potential and high collapsibility (Gibbs, Bara 1967). Contamination by industrial effluents would therefore deteriorate the quality of soil as an engineering material.

\subsection{Effect of contamination on soil specific gravity}

The effect of contaminants on specific gravity of both soils is summarized in Figure 8. In general, the specific gravity of $\mathrm{CH}$ soils was observed to decrease slightly with the addition of contaminants. Quantitatively, the specific gravity of $\mathrm{CH}$ soil decreased by $1.4 \%$ and $2.3 \%$ with the addition of acidic and basic contaminants, respectively. However, the specific gravity of CL soil was unaffected by the addition of contaminants. This behavior can be associated with both the effluents having nearly the same specific gravity as CL soil.

\section{3. $\mathrm{pH}$ value of contaminated soil}

The industrial effluents used in this study were recovered from a textile and a paper industry. The effluent recovered from textile industry was basic in nature whereas the effluent from paper industry was acidic in nature. The overall $\mathrm{pH}$ of soil samples was affected accordingly with the addition of these effluents. Effect of contaminant on $\mathrm{pH}$ is summarized in Figure 9. The $\mathrm{pH}$ of $\mathrm{CL}$ and $\mathrm{CH}$ soil samples increased by $5.3 \%$ and $5.7 \%$ with the addition of $20 \%$ textile waste effluent. On the contrary, the $\mathrm{pH}$ of both the soil samples decreased with the addition of effluent from paper industry because of its acidic nature. The observed decrease in $\mathrm{pH}$ of $\mathrm{CL}$ and $\mathrm{CH}$ soil samples with $20 \%$ contamination of paper effluent was $5.3 \%$ and $7.1 \%$ respectively. This behavior is consistent with the findings of Sunil et al. (2009).

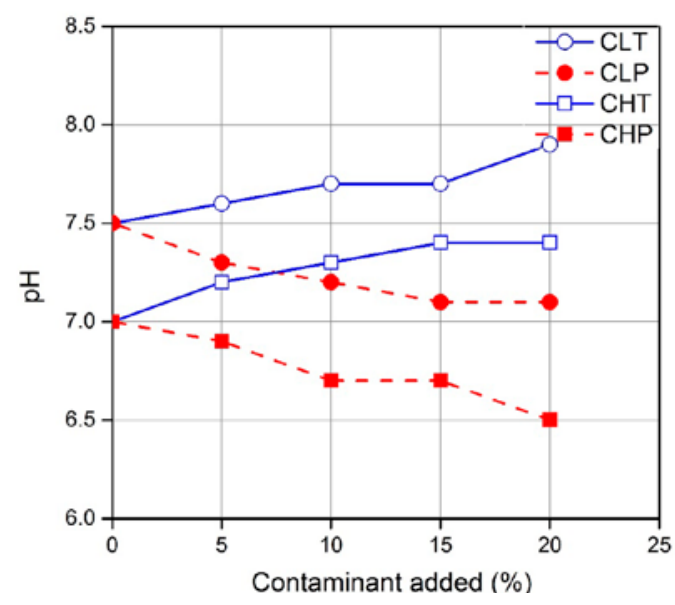

Fig. 9. Variation of $\mathrm{pH}$ with concentration of contaminant 


\subsection{Effect of contamination on electrical conductivity}

The effect of contamination addition on the electrical conductivity of both soils is illustrated in Figure 10. The electrical conductivity of both the soil samples increased with the addition of contaminants. Quantitatively, the specific gravity of CL soil increased by $1.2 \%$ and $1.4 \%$ with the addition of acidic and basic contaminants respectively. However the corresponding increase in electrical conductivity of $\mathrm{CH}$ soils was more pronounced and it was $4.0 \%$ and $5.8 \%$ for acidic and basic contamination addition respectively. The increase in electrical conductivity of contaminated soils compared to the parent soil, may be associated to the presence of more free ions in the acidic/basic contaminated soils.

\subsection{Compaction characteristics of contaminated soils}

The effect of contamination addition on the compaction characteristics of both soils is represented in Figures 11 and 12. In general, the optimum moisture content was observed to increase by around $10 \%$ for CL soil and around 7.5\% for $\mathrm{CH}$ soil with the addition of contaminants. On contrary, maximum dry unit weights of both cohesive soils were found to decrease with the addition of contaminants. The decrease in maximum dry unit weights of both the soils with the addition of $20 \%$ acidic/basic effluent was quite identical at around $4 \%$.

The variation in the compaction characteristics of cohesive soils because of contaminant addition can be explained on the basis of soil plasticity. Optimum moisture content of cohesive soils increases whereas the maximum dry unit weight obtained through compaction tests decreases with plasticity index of soil (Berawala, Solanki 2010; Pandian et al. 1997; Sridharan, Nagaraj 2005). As discussed previously in Section 4.1, increase in contamination concentration makes the soil more plastic, thereby leading to an increase in optimum moisture content and a decrease in maximum dry unit weight. From engineering applications perspective, this means a high water demand to attain optimum moisture in the field; which, in general, increases the project cost and is typically undesirable. In other words, soil with high contaminant concentration would be difficult to compact and would yield a lower unit weight compared to uncontaminated soil under the same compactive effort and moisture conditions.

\subsection{Effect of contamination on unconfined compressive strength}

Addition of contamination to cohesive soils was found to adversely affect shear strength as illustrated in Figure 13. In general, unconfined compressive strength of both CL and $\mathrm{CH}$ soils showed a slight decrease on the addition of effluent contamination. Unconfined compressive strength of $\mathrm{CL}$ and $\mathrm{CH}$ soils decreased by around $5 \%$ and $6 \%$, respectively with contamination. The reduction of strength due to contamination is attributed to possible breakage of internal bonds (Umesha et al. 2012). Typical photographs of specimens before and after the unconfined compression test are shown in Figure 14.

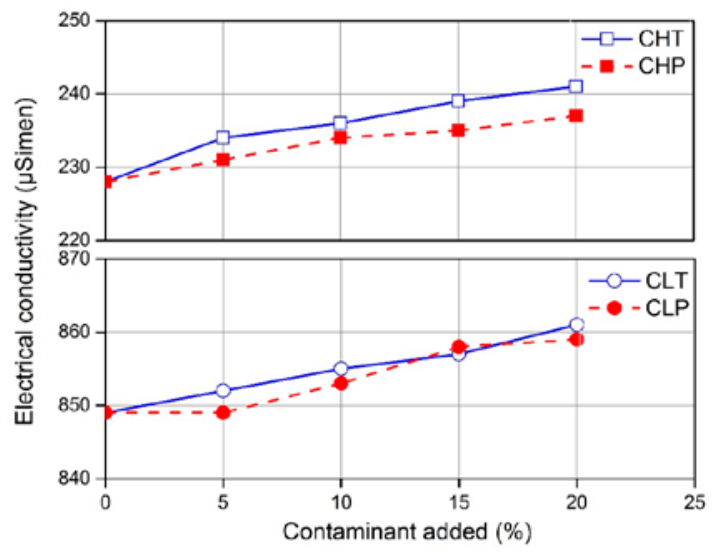

Fig. 10. Effect of contamination on electrical conductivity of soil

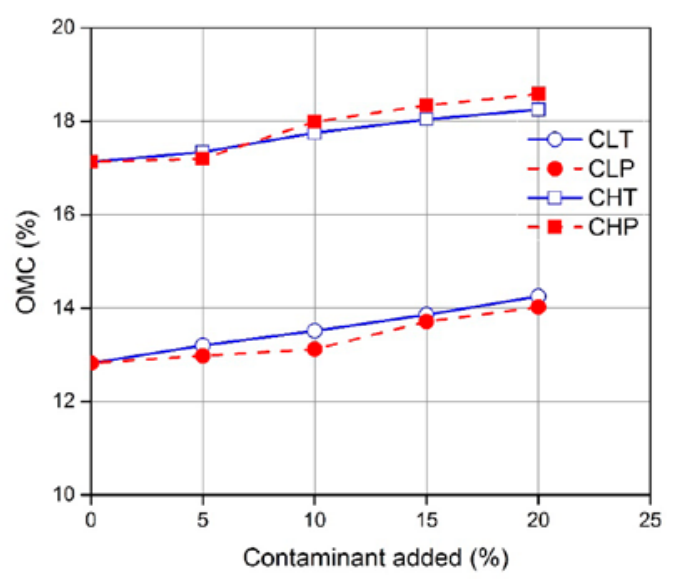

Fig. 11. Variation of OMC with effluent contamination

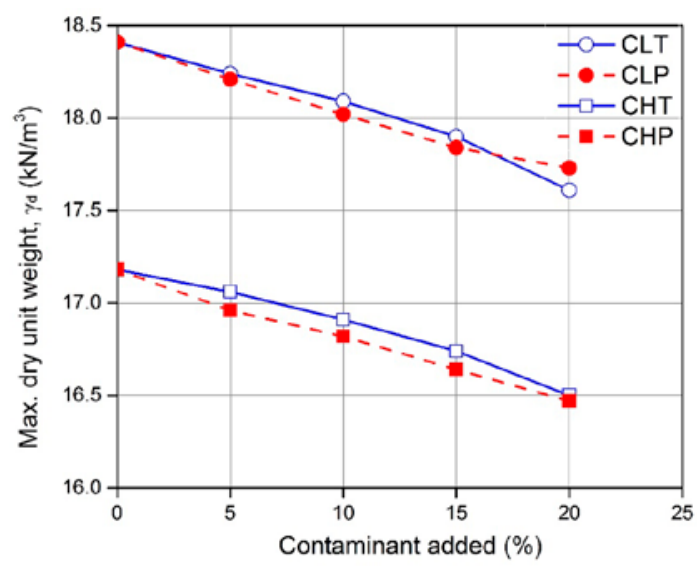

Fig. 12. Variation of maximum dry unit weight with effluent contamination 


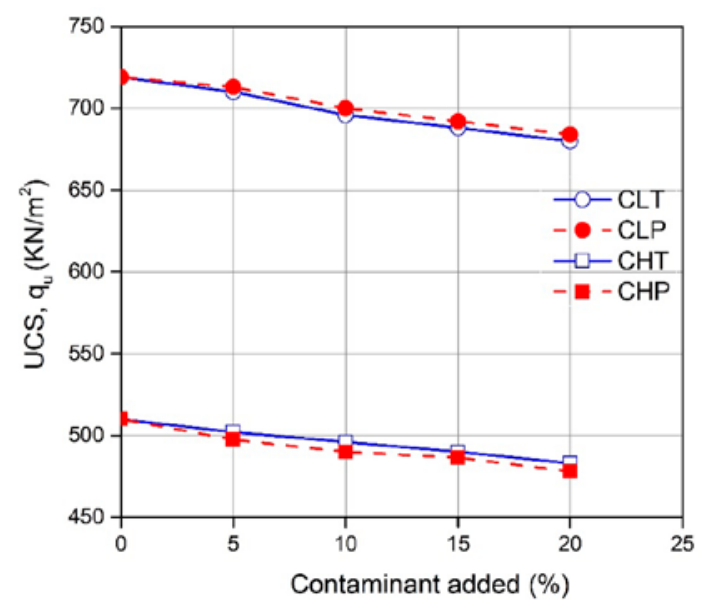

Fig. 13. Effect of contamination on unconfined compressive strength

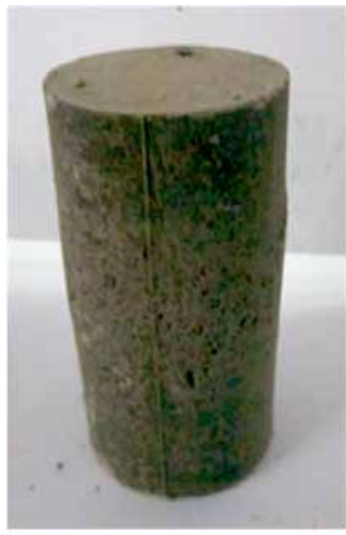

(a)

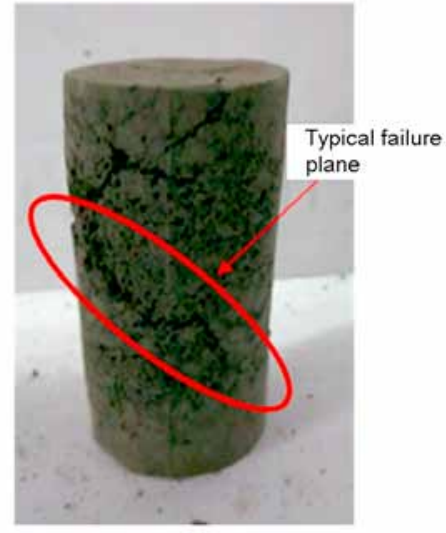

(b)
Fig. 14. Typical unconfined compression test specimens (a) before test (b) after test

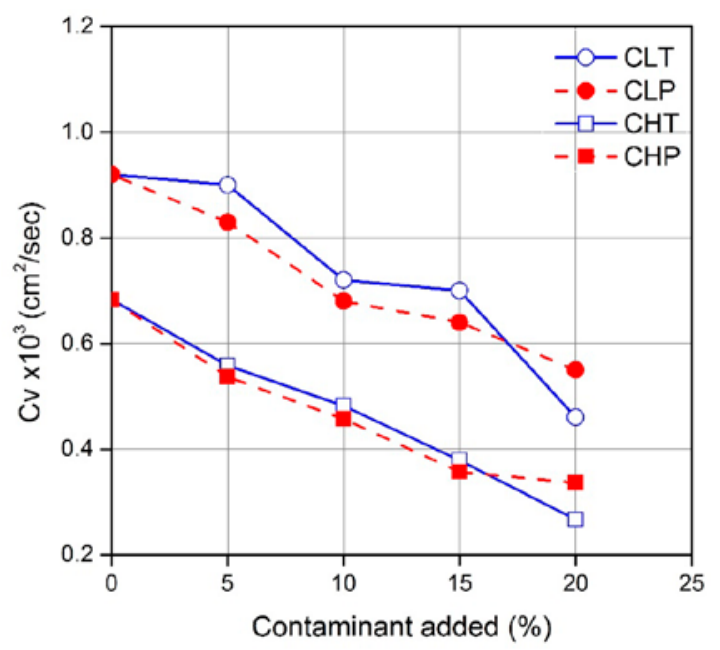

Fig. 15. Variation of $\mathrm{Cv}$ with the addition of acidic and basic contaminants

\subsection{Consolidation characteristics of contaminated soils}

The consolidation characteristics of industrial effluent contaminated soils were evaluated by performing onedimensional consolidation test on original, and contaminated soil specimens. The effect of effluent contamination on the rate of consolidation (represented by coefficient of consolidation, $\mathrm{C}_{\mathrm{v}}$ ), and the magnitude of consolidation (represented by compression index, $\mathrm{C}_{c}$ ) are illustrated in Figures 15 and 16 respectively.

With the addition of acidic (paper industry) and basic (textile industry) contaminants, $\mathrm{C}_{\mathrm{v}}$ of CL soil decreased by $40.2 \%$ and $50.0 \%$, and that of $\mathrm{CH}$ soil decreased by $50.8 \%$ and $60.9 \%$ respectively. Time required for the consolidation of contaminated soil would therefore be greater than that required for the completion of same degree of consolidation in the parent soil. $\mathrm{C}_{\mathrm{v}}$ is an indirect measure of soil permeability as well. Decrease in $\mathrm{C}_{\mathrm{v}}$ also indicates a reduction in the hydraulic conductivity of contaminated soil. Suspended solids in the industrial waste typically have very small particle size. These particles might clog the inter-particle space in parent soil sample thereby reducing the hydraulic conductivity.

The compression index $\left(\mathrm{C}_{\mathrm{c}}\right)$, represented in Figure 15 , demonstrates an increase in the magnitude of consolidation with contaminant concentration. The increase in $\mathrm{C}_{\mathrm{c}}$ of CL soil ranged from $7.5 \%$ to $11.3 \%$ whereas the corresponding increase for $\mathrm{CH}$ soil was from $9.4 \%$ to $11.1 \%$, for $20 \%$ addition of acidic/basic contaminant. This indicates the consolidation potential of contaminated soils to be higher than uncontaminated soils. The same behavior could also be deduced from the increase in soil plasticity with effluent contamination (Fig. 5), since $\mathrm{C}_{\mathrm{c}}$ is a direct function of soil plasticity (Terzaghi, Peck 1948).

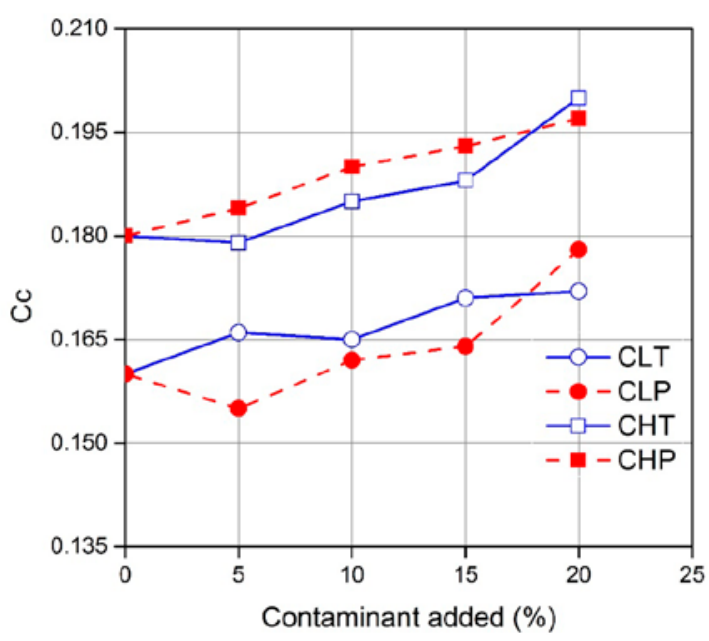

Fig. 16. Variation of $\mathrm{Cc}$ with the addition of acidic and basic contaminants 


\section{Conclusions}

The main objective of this research was to study the effects of industrial contamination on local cohesive soils. The test results showed a significant change in the geotechnical properties of contaminated soils when compared with the parent soil samples. The conclusions drawn from this research work are as follows:

- The increase in liquid limit and plasticity index of cohesive soils is mainly attributed towards an increase in specific surface area of soil due to contaminant addition which leads to high adsorption of water affecting the Atterberg's limits values.

- Addition of acidic and basic contaminants vary the $\mathrm{pH}$ of soil accordingly. Due to the presence of more free ions in contaminated soils, electrical conductivity is also increased.

- Due to chemical reaction between contaminant and soil particles, soil becomes more plastic in nature which causes a decrease in maximum dry unit weight and an increase in optimum moisture content. A corresponding decrease in unconfined compressive strength of contaminated soils was also observed.

- The chemical reaction between effluents and soil particles also affect the consolidation characteristics of soil. Contamination makes the soil highly compressible as indicated by an increase in compression index. However, a decrease in the coefficient of consolidation of contaminated soils indicate a decrease in the permeability of contaminated soil. This implies that contaminated soils would take longer to accomplish a certain degree of consolidation.

- In general, the soil properties have been found to deteriorate because of being contaminated by industrial effluents. Special considerations would therefore be required for constructing on such soils. The loss of bearing capacity indicated by a decrease in unconfined compressive strength, and an expected increase in the magnitude of consolidation settlement should be carefully considered while designing foundations on such soils. The increased chemical aggressivity of contaminated soils can also be a concern for foundation concrete.

\section{Acknowledgements}

The University of Engineering and Technology, Lahore and Institute of Environmental Engineering and Research, Lahore (Pakistan) are gratefully acknowledged for the financial and technical assistance.

\section{References}

Adebisi, S.; Fayemiwo, K. 2010. Pollution of Ibadan soil by industrial effluents, New York Science Journal 3(10): 37-41.

Berawala, K.; Solanki, C. 2010. Empirical correlations of expansive soils parameters for the Surat Region, in Indian Geotechnical Conference, 16-18 December 2010, Mumbai, India.

Bond, R. G.; Straub, C. P.; Prober, R. 1973. Water supply and treatment. Ohaio: CRC Press.

Choudhury, A. K. R. 2006. Textile preparation and dyeing. Enfield: Science Publishers.

Gibbs, H. J.; Bara, J. P. 1967. Stability problems of collapsing soil, Journal of Soil Mechanics \& Foundations Division, ASCE 93(4): 577-594.

Gratchev, I.; Towhata, I. 2009. Effects of acidic contamination on the geotechnical properties of marine soils in Japan, in ISOPE-2009 Osaka: $19^{\text {th }}$ International Offshore (Ocean) and Polar Engineering Conference, 21-26 June 2009, Osaka, Japan.

Jia, Y.; Wu, Q.; Shang, H.; Yang, Z. N.; Shan, H. 2011. The influence of oil contamination on the geotechnical properties of coastal sediments in the Yellow River Delta, China, Bulletin of Engineering Geology and the Environment 70(3): 517-525. https://doi.org/10.1007/s10064-011-0349-8

Khamehchiyan, M.; Charkhabi, A. H.; Tajik, M. 2007. Effects of crude oil contamination on geotechnical properties of clayey and sandy soils, Engineering Geology 89(3): 220-229. https://doi.org/10.1016/j.enggeo.2006.10.009

Kumar, A. 2005. Concepts of biophysics. New Delhi: APH Publishing Corporation.

Naeini, S.; Jahanfar, M. 2011. Effect of salt solution and plasticity index on undrain shear strength of clays, World Academy of Science, Engineering and Technology 49: 982-986.

Nazir, A. K. 2011. Effect of motor oil contamination on geotechnical properties of over consolidated clay, Alexandria Engineering Journal 50(4): 331-335. https://doi.org/10.1016/j.aej.2011.05.002

NEQS. 2000. National environmental quality standards. Environmental Protection Agency, Government of Pakistan, Islamabad.

Olgun, M.; Yildiz, M. 2010. Effect of organic fluids on the geotechnical behavior of a highly plastic clayey soil, Applied Clay Science 48(4): 615-621. https://doi.org/10.1016/j.clay.2010.03.015

Pandian, N.; Nagaraj, T.; Manoj, M. 1997. Re-examination of compaction characteristics of fine-grained soils, Geotechnique 47(2): 363-366. https://doi.org/10.1680/geot.1997.47.2.363

Patel, A. 2011. Study of Geotechnical properties of black cotton soil contaminated by castor oil and stabilization of contaminated soil by sawdust, in National Conference on Recent Trends in Engineering \& Technology, 13-14 May 2011, Gujrat, India.

Reddy, K. R.; Hettiarachchi, H.; Gangathulasi, J.; Bogner, J. E. 2011. Geotechnical properties of municipal solid waste at different phases of biodegradation, Waste Management 31(11): 2275-2286.

Sridharan, A.; Nagaraj, H. 2005. Plastic limit and compaction characteristics of finegrained soils, Proceedings of the ICEGround Improvement 9(1): 17-22.

https://doi.org/10.1680/grim.2005.9.1.17 
Sunil, B.; Nayak, S.; Shrihari, S. 2006. Effect of pH on the geotechnical properties of laterite, Engineering Geology 85(1): 197-203. https://doi.org/10.1016/j.enggeo.2005.09.039

Sunil, B.; Shrihari, S.; Nayak, S. 2009. Shear strength characteristics and chemical characteristics of leachate-contaminated lateritic soil, Engineering Geology 106(1): 20-25.

https://doi.org/10.1016/j.enggeo.2008.12.011
Terzaghi, C.; Peck, R. B. 1948. Soil mechanics in engineering practice. New York: John Wiley \& Sons.

Umesha, T. S.; Dinesh, S. V.; Sivapullaiah, P. V. 2012. Effects of acids on geotechnical properties of black cotton soil, International Journal of Geology 6(3): 69-76.

Muhammad Imran KHAN. MSc Geotechnical Engineering. PhD Scholar, Department of Civil Engineering and Applied Mechanics, Montreal, Canada. Lecturer, Civil Engineering Department, University of Engineering and Technology, Lahore. Research Interest: Contaminated Soils, Laboratory testing of soils, Foundation Engineering, Soil Structure Interaction. No. of publications: 0 . No. of attended conferences: 2 .

Muhammad IRFAN. PhD Geotechnical Engineering. Assistant Professor, Civil Engineering Department, University of Engineering and Technology, Lahore.

Research Interest: Finite element modeling of soil-structure interaction, Unsaturated soil mechanics, Rain-induced landslides, Landslide early warning, In-situ soil characterization, Soil dynamics, Foundation Engineering. No. of publications: 37. No. of attended conferences: 18.

Mubashir AZIZ. PhD Geotechnical Engineering. Assistant Professor, College of Engineering, Al Imam Mohammad Ibn Saud Islamic University, Riyadh.

Research Interest: Soil Mechanics, Engineering Geology, Geotechnical Earthquake Engineering. No. of publications: 30. No. of attended conferences: 18 .

Ammad Hassan KHAN. PhD Geotechnical Engineering. Professor \& Chairman, Transportation Engineering Department, University of Engineering and Technology, Lahore.

Research Interest: Geotechnical Investigation, In-situ and Laboratory Testing, Transportation Engineering Materials, Advances and Trends in Geotechnical Engineering. No. of publications: 18. No. of attended conferences: 11. 